\title{
OPTIMALISASI PERSEDIAAN BAHAN BAKAR MINYAK INDUSTRI (SOLAR) PADA PT. PRIMA SENTOSA ALAM LESTARI MENGGUNAKAN METODE ECONOMIC ORDER QUANTITY (EOQ)
}

\author{
Santi ${ }^{1}$, A. I. Jaya ${ }^{2}$, dan A. Sahari ${ }^{3}$ \\ 1,2,3Program Studi Matematika Jurusan Matematika FMIPA Universitas Tadulako \\ Jalan Soekarno-Hatta Km. 09 Tondo, Palu 94118, Indonesia. \\ 1santisan666@yahoo.com, 2jayaindraagus@gmail.com, 3agus_sh@yahoo.com
}

\begin{abstract}
PT. Prima Alam Lestari Sentosa is a company engaged in six areas such as transporter fuel, industrial fuel agents pertamina, SPPBE, general construction services, mining contractor, and the procurement of goods and services. In carrying out its production activity is associated with supplies of fuel oil. Where inventory is one of management activities related to storage costs and reservations so that the necessary optimization of inventory. In this study the authors using Economic Order Quantity to optimize the inventory. This study aims is to determine the inventory optimization of fuel oil at PT. Prima Alam Lestari Sentosa and compared it with the fuel inventory optimization EOQ method. . PT Prima Alam Lestari Sentosa set the amount every one reservations is 14212.50 liters with the number of bookings 317 timeseach year and the total cost of supply is $R p .710 .304 .976,352,-$ while when using the $\mathrm{EOQ}$ method, the ordering amount is 20.225 liters with the number of bookings are as 223 times each year and the total inventory cost $R p .668 .280 .488,26$,-. Thus, in the year of 2016, it is about that the company's policy when using the EOQ method is equal to $R p .24 .024 .488,092$.
\end{abstract}

Keywords : : EOQ Method, Inventory, Optimization.

\section{ABSTRAK}

PT. Prima Sentosa Alam Lestari merupakan perusahaan yang bergerak dalam enam bidang yaitu transportir BBM, agen BBM industri pertamina, SPPBE, jasa kontruksi umum, kontraktor tambang, dan pengadaan barang dan jasa. Kegiatan produksi dari perusahaan sangat berkaitan dengan persediaan BBM. Dimana persediaan merupakan salah satu kegiatan manajemen yang berhubungan dengan biaya penyimpanan dan pemesanan sehingga diperlukan optimalisasi persediaan. Dalam penelitian ini penulis menggunakan metode Economic Order Quantity untuk mengoptimalkan persediaan tersebut. Penelitian ini bertujuan untuk mengetahui optimalisasi persediaan bahan bakar minyak pada PT. Prima Sentosa Alam Lestari yang akan dibandingkan dengan optimalisasi persediaan bahan bakar minyak menggunakan metode EOQ. PT Prima Sentosa Alam Lestari menetapkan jumlah pemesanan setiap kali pesan sebesar 14.212,50 liter dengan jumlah pemesanan sebanyak 317 kali setiap tahun dan total biaya persediaannya sebesar $R p .710 .304 .976,352,-$ sedangkan bila menggunakan metode EOQ jumlah pemesanannya sebesar 20.225 liter dengan jumlah pemesanan sebanyak 223 kali setiap tahun dan total biaya persediaannya sebesar $R p .668 .280 .488,26,-$. Jadi, didapatkan selisih biaya dari kebijakan perusahaan bila menggunakan metode EOQ yaitu sebesar Rp. 24.024.488,092, di tahun 2016.

Kata kunci : Metode EOQ, Persediaan, Optimalisasi. 


\section{PENDAHULUAN}

\subsection{Latar Belakang}

Dalam menjalankan aktifitasnya suatu perusahaan perdagangan harus menjaga persediaan BBM industri yang cukup agar kegiatan operasi perusahaannya dapat berjalan dengan lancar dan efisien. Yang perlu diperhatikan dalam hal ini adalah agar bahan baku yang diperlukan tetap tersedia sehingga kelancaran produksi pun tetap terjamin. Namun jumlah persediaan tidak dalam jumlah yang terlalu besar karena akan berakibat pada modal yang tertanam dalam persediaan dan biaya persediaan terlalu besar. Di sisi lain juga jika jumlah persediaan terlalu sedikit akan berpeluang terjadinya kehabisan persediaan yang berakibat berhentinya proses kerja pada suatu perusahaan.

Economic Order Quantity adalah volume atau jumlah pembelian yang paling ekonomis untuk dilakukan pada setiap kali pembelian (Prawirosentono, 2001:49). Metode EOQ berusaha mencapai tingkat persediaan yang seminimum mungkin, biaya rendah dan mutu yang lebih baik. Perencanaan metode EOQ dalam suatu perusahaaan akan mampu meminimalisasi terjadinya out of stock sehingga tidak mengganggu proses dalam perusahaan dan mampu menghemat biaya persediaan yang dikeluarkan oleh perusahaan karena adanya efisisensi persediaan bahan baku di dalam perusahaan yang bersangkutan.

PT Prima Sentosa Alam Lestari berdiri pada tanggal 26 juni 1993, Perusahaan ini bergerak dalam enam bidang yaitu transportir BBM, agen BBM industri pertamina, SPPBE, jasa kontruksi umum, kontraktor tambang, dan pengadaan barang dan jasa. Sejak 2010, tepatnya tanggal 24 Juli perusahaan ini dipercayakan oleh PT. PERTAMINA sebagai agen BBM Industri di wilayah Sulawesi Tengah sekaligus Transportir diwilayah Sulawesi Tengah, Gorontalo, Sulawesi Tenggara dan Sulawesi Utara. Perusahaan ini harus menjaga persediaan yang ekonomis, karena jika persediaan terlalu sedikit maka perusahaan tersebut akan beresiko mengalami kehabisan persediaan BBM industrinya, hal ini mengakibatkan perusahaan kehilangan kesempatan keuntungan dan pelanggan. Akan tetapi jika terlalu banyak pula akan mengakibatkan terlalu banyak modal yang dipakai untuk penyimpanan.

\subsection{Rumusan Masalah}

Dari latar belakang di atas peneliti dapat merumuskan permasalahan yaitu bagaimana menentukan jumlah persediaan dan biaya total persediaan BBM Industri yang tepat dan ekonomis pada PT Prima Sentosa Alam Lestari dengan menggunakan metode Economic Order Quantiry (EOQ)?. 


\subsection{Batasan Masalah}

1. Penelitian ini dibatasi pada penggunaan BBM industri dalam satu periode yaitu pada tahun 2016 khusus di kota Palu.

2. Data yang diambil dalam penelitian ini adalah:

a. Jumlah dan biaya pemesanan BBM dalam satu periode (2016).

b. Harga BBM per liter.

c. Frekuensi dalam satu periode pembelian.

\section{TINJAUAN PUSTAKA}

\subsection{Pengertian Persediaan}

Persediaan adalah sumber daya menganggur (ide resouce) yang menunggu proses lebih lanjut. Yang di maksud dengan proses lebih lanjut tersebut adalah berupa kegiatan produksi pada sistem manufaktur, kegiatan pemasaran pada sistem distribusi ataupun kegiatan konsumsi pangan pada istem rumah tangga (Nasution dan Arman Hakim, 2003).

\subsection{Metode Economic Order Quantity (EOQ)}

\subsubsection{Pengertian Metode Economic Order Quantity}

EOQ merupakan metode persediaan yang menentukan jumlah pemesanan berdasarkan biaya pemesanan dan peyimpanan yang minimal atau dengan kata lain EOQ merupakan volume atau jumlah pembelian yang ekonomis untuk dilaksanakan pada setiap pembelian (P. Siagian, 1987).

\subsubsection{Perumusan Metode EOQ}

EOQ dapat diterapkan bila anggaan-anggapan berikut terpenuhi:

a) Hanya satu macam barang yang diperhitungkan (BBM Solar).

b) Kebutuhan (permintaan) setiap periode diketahui, relatif tetap dan terus menerus.

c) Barang yang dipesan diasumsikan langsung dapat tersedia atau berlimpah.

d) Waktu tenggang (lead time) bersifat konstan.

e) Setiap pesanan diterima dalam sekali pengiriman dan langsung dapat digunakan.

f) Tidak ada pesanan ulang (beck order) karena kehabisan persediaan.

g) Tidak ada quantity discount.

(Nasution, Arman .H dan Prasetiawan, 2008) 


\subsubsection{Persediaan Pengaman}

Persediaan pengaman sering juga disebut sebagai persediaan besi (iron stock) adalah suatu persediaan yang dicadangkan sebagai pengaman dari kelangsungan proses produksi perusahaan untuk menghindari terjadinya kekurangan barang. Persedaaan pengaman ini merupakan sejumlah unit tertentu dimana unit ini akan tetap dipertahankan walau bahan bakunya dapat berganti dengan yang baru. Untuk menetukan persediaan pengaman ini dipergunakan analisis statistk dengan melihat dan memperhitungkan penyimpangan-penyimpangan yang sudah terjadi antara pikiran bahan baku dengan pemakaian sesungguhnya dapat diketahui besarnya standar dari penyimpanan tersebut.

Persediaan pengaman berfungsi untuk melindungi atau menjaga kemungkinan terjadinya kekurangan barang, misalnya karena penggunaan barang yang lebih besar dari perkiraan semula atau keterlambatan dalam penerimaan barang yang dipesan. (Herjanto, 1999).

\subsubsection{Pemesanan Kembali}

Saat harus diadakan pemesanan kembali sehingga kedatangan atau penerimaan barang yang dipesan tepat waktu (di mana persediaan di atas persediaan pengaman sama dengan nol). Titik pemesanan ulang dapat ditetapkan dengan menjumlahkan penggunaan selama waktu tenggang di tambah dengan persediaan pengaman. (Herjanto, 1999).

\subsubsection{Total Inventory Cost}

Total Inventory Cost merupakan total keseluruhan dari biaya-biaya yang timbul akibat dari persediaan yang dikeluarkan oleh perusahaan

\section{PROSEDUR PENELITIAN}

Prosedur dalam penelitian ini adalah:

1. Melakukan studi literatur dengan m mengumpulkan materi dan dari buku-buku, artikel, dan jurnal yang didapatkan dari perpustakaan dan internet.

2. Menganalisa masalah

3. Memulai penelitian

4. Mengambil data

5. Menentukan variabel dari setiap masalah

6. Mengolah data menggunakan metode EOQ

7. Menyimpulkan hasil penelitian

8. Selesai. 


\section{HASIL DAN PEMBAHASAN}

\subsection{Data Penelitian}

Perusahaan melakukan pemesanan bahan bakar terhitung setiap hari sehingga waktu tunggu kedatangan BBM yang dipesan yaitu satu hari. Frekuensi pemesanan dalam satu tahun sebanyak 317 jika dikurangi dengan hari libur yaitu setiap hari minggu.

Data persediaan dan komponen-komponen biaya yang diperoleh berdasarkan penelitian dapat dilihat pada tabel-tabel di bawah ini:

Tabel 1 : Tabel Persediaan BBM (Periode Tahun 2016)

\begin{tabular}{|l|l|c|}
\hline No & \multicolumn{1}{|c|}{ BULAN } & $\begin{array}{c}\text { PERSEDIAAN } \\
\text { (Liter) }\end{array}$ \\
\hline 1. & Januari & 269.720 \\
\hline 2. & Februari & 425.848 \\
\hline 3. & Maret & 557.370 \\
\hline 4. & April & 449.206 \\
\hline 5. & Mei & 213.410 \\
\hline 6. & Juni & 262.986 \\
\hline 7. & Juli & 231.400 \\
\hline 8. & Agustus & 281.482 \\
\hline 9. & September & 236.069 \\
\hline 10 & Otober & 460.961 \\
\hline 11. & November & 543.021 \\
\hline 12. & Desember & 473.892 \\
\hline & Jumlah (D) & 4.505 .365 \\
\hline & Rata-rata & 375.447 \\
\hline
\end{tabular}

Sumber : PT. Prima Sentosa Alam Lestari

Tabel 2 : Data Biaya Pemesanan Per satu kali pesan

\begin{tabular}{|l|l|}
\hline Jenis Biaya & Jumlah \\
\hline Pembuatan PO dan Atministrasi & Rp.215.000 \\
\hline Bongkar Muat & Rp. 235.000 \\
\hline Ongkos Transportasi & Rp.1.000.000 \\
\hline Total (S) & Rp.1.500.000 \\
\hline
\end{tabular}

Sumber : Hasil wawancara dengan PT. Prima Sentosa Alam Lestari 
Tabel 3 : Data Biaya Penyimpanan Per satu kali pesan

\begin{tabular}{|l|l|}
\hline Jenis Biaya & Jumlah \\
\hline Biaya Perawatan Tangki & Rp.4.808 \\
\hline Biaya Susut & Rp. 9.003 \\
\hline Gaji kariawan & Rp.19.231 \\
\hline Total (H) & Rp.33.042 \\
\hline
\end{tabular}

Sumber : Hasil wawancara dengan PT. Prima Sentosa Alam Lestari

\subsection{Total Biaya Persediaan Menurut Kebijakan Perusahaan}

\subsubsection{Jumlah Pemesanan Bahan Bakar Per Pesan}

Sebelum menghitung total biaya persediaan, terlebih dahulu dihitung jumlah pemesanan bahan bakar per pesan, dengan rumus sebagai berikut:

$$
Q=\frac{D}{F}
$$

$Q=\frac{4.505 .365}{317}$

$=14.212,50$ liter per pesan.

Jadi, dari persamaan (1) diperoleh besarnya jumlah pemesanan bahan bakar yang dilakukan oleh PT Prima Sentosa Alam Lestari dalam sekali pesan yaitu sebesar Rp. 14.212,50 liter per pesan.

\subsubsection{Total Biaya Persediaan Perusahaan}

Agar dapat menghitung total biaya persediaan maka yang harus diketahui terlebih dahulu adalah:

a) Jumlah pemesanan bahan bakar per tahun $(D)=4.505 .365$ liter

b) Jumlah pemesanan per pesan $(Q)=14.212,50$ liter

c) Biaya pemesanan per pesan $(S)=$ Rp. 1.500 .000

d) Biaya penyimpanan per pesan $(H)=$ Rp. 33.042

Dengan mengetahui biaya-biaya persediaan diatas, maka dapat dihitung total biaya persediaan perusahaan sebagai berikut:

$$
\begin{array}{ll}
\text { Biaya pemesanan per tahun } & =\frac{D}{Q} S \\
& =\frac{4.505 .365}{14.212,50} 1.500 .000 \\
& =475.500 .263,852 \\
\text { Biaya penyimpanan pertahun } & =\frac{Q}{2} H \\
& =\frac{14.212,50}{2} 33.042 \\
& =234.804 .12,5 .
\end{array}
$$


Dari hasil perhitungan diatas dapat diketahui biaya pemesanan per tahun yaitu $R p .475 .500 .263,852$,- dan biaya penyimpanan per tahun yaitu $R p .234 .804 .12,5,-$. Untuk mengetahui total biaya persediaan perusahaan dapat dihitung dengan menggunakan persamaan (2) dan persamaan (3) dengan rumus sebagai berikut:

$$
\begin{aligned}
\text { TIC } & =\left[\frac{D}{Q} S\right]+\left[\frac{Q}{2} H\right] \\
& =475.500 \cdot 263,852+234.804 \cdot 12,5 \\
& =R p .710 .304 .976,352 .
\end{aligned}
$$

Dari perhitungan pada persamaan diatas dapat diketahui total biaya persediaan yang harus ditanggung perusahaan selama setahun adalah $R p .710 .304 .976,352$.

\subsection{Analisis Pengendalian Persediaan Berdasarkan Metode EOQ}

\subsubsection{Menghitung Jumlah Pemesanan Bahan Bakar Menurut Metode EOQ}

Jumlah pemesanan bahan bakar yang ekonomis menggunakan metode $E O Q$ adalah sebagai berikut:

$$
\begin{aligned}
Q^{*} & =\sqrt{\frac{2 D S}{H}} \\
& =\sqrt{\frac{2(4.505 .365)(1.500 .000)}{33.042}} \\
& =20.225 \text { liter. }
\end{aligned}
$$

Dari perhitungan pada persamaan diatas dapat diketahui jumlah pemesanan bahan bakar yang ekonomis menurut metode EOQ untuk PT Prima Sentosa adalah sebesar 20.225 liter per pesan.

\subsubsection{Frekuensi Pemesanan}

$$
\begin{aligned}
F & =\frac{D}{Q^{*}} \\
& =\frac{4.505 .365}{20.225} \\
& =222,762 \sim 223 \text { kali. }
\end{aligned}
$$

Dari perhitungan diatas dapat diketahui frekuensi pemesanan bahan bakar dengan menggunakan metode EOQ adalah sebanyak 223 kali pertahun. 


\subsubsection{Persediaan Pengaman (Safety Stock)}

Dalam penelitian ini menghitung persediaan pengaman digunakan metode statistik dengan membandingkan rata-rata pemesanan bahan bakar dengan pemeanan bahan bakar yang sesungguhnya kemudian dicari penyimpangannya.

$$
\begin{aligned}
\sigma & =\sqrt{\frac{\sum(x-\bar{x})^{2}}{n}} \\
& =\sqrt{\frac{174.103 .187 .243}{12}} \\
& =120.451,6456 .
\end{aligned}
$$

Berdasarkan perhitungan penggunaan bahan bakar di atas diperoleh standar deviasi yaitu $\sigma=120.451,6456$. Dan PT Prima Sentosa menggunakan batas toleransi $\alpha=5 \%$ dibawah perkiraan dan diperoleh nilai standar normal deviasi (Z) adalah 1.65. Maka besarnya persediaan pengaman (safety stock) bahan bakar dapat dihitung dengan rumus sebagai berikut:

$S S=Z \sigma$

Dimana, $\mathrm{SS}=$ safety stock (persediaan pengaman)

$Z=$ standar deviasi

$\sigma=$ standar deviasi normal

$S S=Z \sigma$

$=1,65 \times 120.451,6456$

$S S=198.745,21$.

Dari hasil perhitungan di atas dapat diketahui persediaan pengaman (safety stock) bahan bakar yang harus disediakan oleh PT. Prima Sentosa pada tahun 2016 adalah 198.745,21 liter.

\subsubsection{Pemesanan Kembali (Reorder Point)}

Rata-rata pemesanan bahan bakar solar adalah $\frac{4.505 .365}{317}=14.212,50$ liter per pesan. Dalam melakukan pemesanan bahan bakar PT Prima Sentosa memiliki waktu tenggang (lead time) (L) selama satu hari untuk menunggu kedatangan bahan bakar setelah terjadi pemesanan. Maka titik pemesanan kembali dapat dihitung dengan rumus sebagai berikut:

$$
\begin{aligned}
R O P & =d L+S S \\
& =(14.212,50 \text { liter } x 1)+198.745,21 \\
& =212.957,71 \text { liter }
\end{aligned}
$$

Dari hasil perhitungan di atas dapat diketahui bahwa perusahaan harus melakukan pemesanan kembali pada saat persediaan bbm berada pada $212.957,71$ liter. 


\subsubsection{Total Biaya Persediaan (Total Inventory Cost)}

Dari variabel-variabel yang telah dibahas sebelumnya total biaya persediaan dapat dihitung pada persamaan (9) berikut:

$$
\begin{aligned}
T I C & =\sqrt{2 D S} H \\
& =\sqrt{2(4.505 .365)(1.500 .000)(33.042)} \\
& =668.280 .488,26
\end{aligned}
$$

Dari perhitungan pada persamaan (9) di atas total biaya persediaan (total inventory cost) perusahaan menggunakan metode EOQ yaitu sebesar $R p .668 .280 .488,26$

\subsection{Perbandingan Kebijakan Perusahaan dengan Metode EOQ}

perbandingan antara jumlah pemesanan bahan bakar, frekuensi pemesanan, dan total biaya persediaan menurut kebijakan perusahaan berbandingan dengan penggunaan metode EOQ. Untuk lebih jelasnya dapat dilihat pada tabel dibawah ini:

Tabel 5 : Perbandingan Kebijakan Pserusahaan dengan Metode EOQ

\begin{tabular}{|l|l|l|l|}
\hline No & Keterangan & Kebijakan Perusahaan & Metode EOQ \\
\hline 1. & Jumlah Pemesanan BBM Perpesan & $14.212,50$ liter & 20,225 liter \\
\hline 2. & Total Biaya Persediaan Pertahun & Rp. 710.304.976,352 & Rp.668.280.488,26 \\
\hline 3. & Frekuensi Pemesanan & 317 kali pesan & 223 kali pesan \\
\hline 4. & Persediaan Pengaman & - & $198.745,21$ liter \\
\hline 5. & Pemesanan kembali & - & $212.957,71$ liter \\
\hline 6. & Persediaan Maksimum & - & $218.970,21$ liter \\
\hline
\end{tabular}

\section{KESIMPULAN}

Dari hasil penelitian dan pembahasan pada bab sebelumnya, diambil suatu kesimpulan bahwa jumlah pemesanan bahan bakar pada PT Prima Sentosa Alam Lestari yang tepat dan ekonomis bila menggunakan metode EOQ adalah sebesar 20.225 liter per pesan dengan pengematan biaya sebesar Rp. 42.024.488,092.

\section{DAFTAR PUSTAKA}

[1] Fadli, Muhammad, Analisis dan Optimalisasi Persediaan Bahan Bakar Pembangkit Listrik pada PT Kutilang Paksi Mas, JIMT, FMIPA Universitas Tadulako, 2015, Palu.

[2] Herjanto, Eddy, Manajemen Produksi dan Operasi, Grasindo,1999, Jakarta.

[3] Nasution, Arman H, dan Prasetiawan, Yhuda, Perencanaan dan Pengendalian Produksi, Graha IImu, 2008, Yogyakarta.

[4] P. Siagan, Penelitian Operasional Teori dan Praktek, Universitas Indonesia, 1987, Jakarta.

[5] PT. Prima Sentosa Alam Lestari 2016, Palu. 